\title{
Aproximación a los mecanismos de financiación de los gobiernos locales en Antioquia en el marco de la nueva gestión pública*
}

\author{
Approach to the financing mechanisms of local governments in \\ Antioquia in the framework of the new public management
}

\author{
Gleidy A. Urrego Estrada \\ Magister en Hábitat Universidad Nacional de Colombia \\ gleidy.urrego@gmail.com
}

\section{Resumen}

El presente artículo tiene como objetivo aproximarse a la identificación de mecanismos de financiación para los gobiernos locales de Antioquia en el marco de la gestión pública. El tipo de investigación es documental-descriptiva, su diseño se basa en dos fases: i) Revisión bibliográfica, informes y normatividad sobre mecanismos de financiación para gobiernos locales y ii) y análisis de su aplicabilidad en el contexto del departamento de Antioquia. Como resultado se aproxima al estado del arte sobre mecanismos de financiación para los gobiernos locales de Colombia; la relación entre gestión pública y mecanismos de financiación estipulados normativamente para los gobiernos locales de Colombia; el crédito bancario como fuente de financiación para los gobiernos locales de Antioquia y su relación con la sostenibilidad de la deuda pública; y por último Alianzas público-privadas como mecanismo de financiación alterno para los gobiernos locales de Antioquia, en el marco de la gestión pública. A manera de conclusión, los mecanismos de financiación para los gobiernos locales de Antioquia tienen una vinculación a la gestión pública, a partir de tres elementos: I) competencias y capacidades. II) establecer parámetros y definir recursos en diferentes sectores contemplados desde el pan de desarrollo. III) toma de decisiones a partir de conocer cuáles son los mecanismos de financiación a los cuales tiene acceso los gobiernos locales desde la misma normativa y, sobre estos, procurar el desarrollo las Alianzas Público- Privadas.

Palabras clave: Mecanismos de financiación, gestión pública, gobierno locales de Antioquia y alianzas público- privadas

\section{Abstract}

The objective of this article is to approach the identification of financing mechanisms for the local governments of Antioquia in the framework of public management. The kind of research is documentarydescriptive, its designed is based on two phases: i) bibliographic review, reports and normativity on financing mechanisms for local governments and, ii) analysis of its applicability in the context of the department of Antioquia. As a result it approaches the state of the art on financing mechanisms for local governments in Colombia; the relation between public management and financing mechanisms normatively stipulated for Colombian local governments; bank credit as a source of financing for Antioquia's local governments and its relation with sustainability of public debt; and finally public-private alliances as an alternative financing mechanism for Antioquia's local governments, in the framework of public management. As a conclusion, the financing mechanisms for Antioquia's local governments have a link to public management, from three elements: I) competences and abilities. II) establish parameters and define resources on the different sectors contemplated from the development plan. III) making decisions form the awareness of which are the financing mechanisms to which local governments have acce3ss from the same normative and, on these, to seek the development of public-private alliances.

Key Words: Financing mechanisms, public management, Antioquia's local governments and public-private alliances.

\footnotetext{
*Artículo producto de la investigación "Canales Mecanismos de Acceso a la Financiación, Fondeo y Préstamos a Sectores No Aptos para el Sistema Financiero Colombiano El caso del: Sector Agrícola, Construcción, Exportadores, Municipios y Pymes "del grupo de investigacion Observatorio Público del Tecnologico de Antioquia.::www.tdea.edu.coCalle 78B No. $72 \mathrm{~A}$ - 220 Medellín - Colombia. Tel: 4547000
} 


\section{Introducción}

La financiación de los gobiernos locales en Antioquia en el marco de la nueva gestión pública se debe abordar desde las transformaciones y exigencias de la gestión pública, como cumplimiento de objetivos, resultados propuestos y la optimización de los recursos públicos. Esto a través de la modernización no solo de procesos y procedimientos que conlleva el cumplimiento constitucional, especialmente el artículo $2^{\circ}$ de la Carta Política de Colombia de 1991, sino la capacidad que debe adquirir a escala nacional y local los gobiernos para gestionar sus recursos, a su vez, cumpliendo el artículo $311^{\circ}$ de la Constitución.

Así, la financiación de los gobiernos locales en Antioquia parte de la racionalidad administrativa pública que tiene un enfoque privado en cuanto a resultados, el individualismo y la rentabilidad (Guerrero, 1990). Esto es, la Influencia del espíritu empresarial en el sector público (Osborne ${ }^{2}$ y Gaebler 1992), que se fundamenta en bases de transformación de las burocracias públicas en gobiernos públicos con una lógica productiva y eficiente. En esa medida, la financiación del desarrollo local que argumenta el artículo $311^{3}$ de la Constitución, establece para los gobiernos locales en Antioquia a aproximarse a identificar fuente de financiación para sus planes de desarrollo, en cumplimiento de la Ley 152 de 1994.

La importancia del presente artículo radica justamente en reflexionar cuáles son los mecanismos de financiación de mayor relevancia para los gobiernos locales de Antioquia en el marco del modelo de gestión pública. En tanto es necesario abordar la necesidad de una nueva lógica para administrar lo público con base en factores de racionalización y capacidad de innovar en funciones como: cuáles son los beneficiarios de la ejecución del plan de desarrollo local, cómo se prestan los servicios públicos y en especial los recursos utilizados. En esa media, el presente artículo se desarrolla así: parte de una introducción a los principios de la gestión pública, seguido de la aproximación al estado del arte sobre mecanismos de financiación para los gobiernos locales de Colombia. Luego, la relación entre gestión pública y cuáles son los mecanismos de financiación estipulados normativamente para los gobiernos locales de Colombia. Posteriormente, abordar el crédito bancario como la recurrente fuente de financiación para los gobiernos locales de Antioquia y su relación con la sostenibilidad de la deuda pública. Por último, resaltar las alianzas público-privadas como mecanismo de financiación alterno para los gobiernos locales de Antioquia, en el marco de la gestión pública.

\section{Metodología}

El tipo de investigación es documental-descriptiva, su diseño se basa en dos fases: i) Revisión bibliográfica, informes $y$ normatividad sobre mecanismos de financiación para gobiernos locales del departamento de Antioquia, y ii) y análisis de su aplicabilidad. Para la aproximación al estado del arte sobre mecanismos de financiación de los gobiernos locales se realizó una revisión bibliográfica sobre mecanismos de financiación, establecidos en el contexto colombiano y desde una mirada institucional -pública, a partir del año 2000 hasta la fecha.

Asimismo, para el abordaje de la relación entre gestión pública y mecanismos de financiación estipulados normativamente para los gobiernos locales en Antioquia, se consideró el despliegue normativo a escala nacional de estos mecanismos, a partir de la Ley 152 de 1994 (es decir los planes de desarrollo local) y el Decreto 111 de 1996 (la programación y ejecución del presupuesto municipal), en un periodo comprendido entre el año 1996 al 2009. Además revisión y análisis de informes del Departamento Nacional de Planeación sobre informes de gestión municipal.

Para el abordaje del crédito bancario como mecanismo de financiación, y su relación con la sostenibilidad de la deuda pública en el departamento de Antioquia, se seleccionó una muestra de siete gobiernos locales del departamento, elegidos según la categorización municipal abordada en la Ley 617 de 2000, como son: Medellín, Barbosa, Bello, Cañasgordas, Caucasia, Caldas y Apartadó, a su vez se revisaron. Además revisión y análisis de la Contraloría General de Antioquia (2012) con el Informe fiscal y financiero de los municipios de Antioquia. Un municipio por categoría que va de especial hasta sexta y con una periodicidad del año 2009 al 2012, en consideración con la Ley 617 de 2000, Ley 358 de 1997 y Decreto reglamentario 696 de 1998. Para el aparte de las Alianzas Público-Privadas se indicó un caso, el proyecto "Circuito de los embalses" en Antioquia.

\section{Resultados}

\section{Principios de la gestión Pública}

La gestión pública está en el marco de los mecanismos de financiación en la Administración Pública moderna, exige un Estado gerencial con capacidad de administrar lo público, bajo enfoques tayloristas de eficiencia y eficacia. Se ha agregado condiciones de transpa-

1 - Son fines esenciales del Estado: servir a la comunidad, promover la prosperidad general y garantizar la efectividad de los principios, derechos y deberes consagrados en la Constitución; facilitar la participación de todos en las decisiones que los afectan y en la vida económica, política, administrativa y cultural de la Nación; defender la independencia nacional, mantener la integridad territorial y asegurar la convivencia pacífica y la vigencia de un orden justo.

2 - David Osborne, en septiembre de 1994, era el asesor principal del Vicepresidente Al Gore, para el diseño y la elaboración de un informe para la Revisión del Rendimiento anual "National Performance Review NPR". El objetivo principal del informe era el de resaltar la transformación del funcionamiento del gobierno federal y abaratar sus costos utilizando la estrategia del llamado gobierno empresarial.

3 - Al municipio como entidad fundamental de la división político-administrativa del Estado le corresponde prestar los servicios públicos que determine la ley, construir las obras que demande el progreso local, ordenar el desarrollo de su territorio, promover la participación comunitaria, el mejoramiento social y cultural de sus habitantes y cumplir las demás funciones que le asignen la Constitución y las leyes. 
rencia y responsabilidad, suscrito en el marco del "Conceso de Washington" a principios de los noventa. En este Consenso esbozó la estrategia Norteamérica de neoliberalismo económico, con temas destacados en el sector público, como: I) cambios en las prioridades del gasto público II) desregularizaciones III) disciplina presupuestaria y IV) privatizaciones. Además, dicho Consenso impulsó y fomentó la apertura del sector privado en la esfera pública, en la medida que el sistema burocrático se desgataba y perdía legitimidad sus procesos y estructuras.

De ahí que se incorporó técnicas de la empresa privada en el sistema burocrático. Para Max Weber (1964-1920) la política occidental, sobre todo el Estado, debía regirse por la racionalidad, esto es, las políticas delimitan el poder, la articulación de estamentos, el oligopolio de los de medios de administración y especificación de poderes en el Estado constitucionalista (Paolo Portinaro, 2003). Precisamente, la gestión pública en el marco del Estado Constitucional y desde la desregularización que propuso el "Conceso de Washington" tiene "como fuentes de inspiración teórica: la economía y la gestión privada" (Hunges, 1996, p.119).

La gestión pública revela la modernización del Estado colombiano a partir de la capacidad que deben tener los gobiernos locales para responder a necesidades del entorno y esta capacidad es fiscal y administrativa. Tanto los enfoques taylorista y económicos sean quienes orienten la garantía del deber constitucional por parte de la administración local, en un contexto de internacionalización de la economía y la globalización del mercado, es decir, flujo de capital, saber tecnológico, funcionalismo estatal hacia la racionalización de los recursos, especialmente los egresos, estructuras y procesos administrativos. Para el Departamento Nacional de Planeación y la Escuela Superior de Administración Pública (2007) señalan que la gestión pública:

Está directamente asociado a los resultados que logre una Administración, y se ha definido como: proceso dinámico, integral, sistemático y participativo, que articula la planificación, ejecución, seguimiento, evaluación, control y rendición de cuentas de las estrategias de desarrollo económico, social, cultural, tecnológico, ambiental, político e institucional de una Administración, sobre la base de las metas acordadas de manera democrática. (p.11)

Ahora bien, la gestión pública se concibe desde las finanzas públicas, el tamaño y el modelo de la organización estatal antecedido por la insuficiencia de recursos financieros para suplir la demanda social del Estado de bienestar. En respuesta, la gestión pública se enfoca en reformas político-administrativas que precisen el tamaño y funciones del aparato estatal manifiesto en los gobierno locales, como señala Brugue y Subirats (1996): "el sector público presenta problemas de ineficiencia, de excesivo gasto, de poca capacidad de respuestas o de cerrazón organizativa" (p.15). Por su parte, para Guerrero (2008) la gestión pública es la respuesta para superar la crisis administrativa y fiscal de los gobiernos, ya que es sinónimo de innovación estatal, al señalar:

No en razón de una lógica instrumental y de control de los procesos, sino de una lógica política encaminada a la resolución de los conflictos que se manifiestan en la vida política, por participativa, y que por lo tanto, más que meticulosidad procedimental, exige inventiva y capacidad de innovación, según lo demande la lógica de los mismos procesos políticos. (p. 54).

La capacidad de innovación en el quehacer público constituye y caracteriza la gestión como instrumento de gobierno hacía la consolidación de autonomía, el trabajo por objetivos y un margen de holgura administrativa y fiscal para la toma de decisiones por parte del gerente público. En esa medida, toda la actividad gubernamental y las demandas ciudadanas son acogidas en la conciliación de los intereses privados sobre los públicos. Es así como en Omar Guerrero (1990), la gestión pública o la new public management es el enfoque del nuevo manejo público, es esto es, la capacidad gubernamental de mirar introspectivamente los procesos de la administración pública, como ciencia del accionar administrativo entre lo público, político y social. Asimismo, para Gunn (1996) la gestión pública:

Acepta que el sector público comparte con el privado la necesidad de lograr objetivos de la forma más económica y más eficiente posible a través de estrategias coherentes, de tácticas y de estructuras apropiadas, de un personal motivado o de técnicas gerenciales adecuadas para desplegar y controlar la utilización de recursos organizativos financieros, humanos, materiales, informativos, etc. (p.43).

En esa medida, al momento de tener un panorama político-presupuestario sobre la financiación de los gobiernos locales, la capacidad administrativa en gestionar fuentes de recursos y gasto que promulga la gestión pública (Guerrero, 1990), se ve limitada a procesos políticos-administrativos que tiene cada gobierno local por asumir y cumplir la norma constitucional. Por tanto, es necesario consolidar cuáles son los mecanismos de financiación a los cuales tiene acceso los gobiernos locales desde la misma normativa, que posibilite la discusión y aproximación a la implementación de un mecanismo alterno, desde lo que plantea la gestión pública: eficiencia y eficacia en la administración de los recursos. Razón por la cual es relevante identificar cuáles son los actuales mecanismos de financiación para los gobiernos locales de Antioquia en el marco de la gestión pública, en especial resaltar las alianzas público-privadas como un mecanismo de financiación innovador en materia político-presupuestaria. 


\section{Aproximación al estado del arte sobre mecanismos de financiación para los gobiernos locales en Colombia}

El Departamento Nacional de Planeación DNP (2003) presentó el panorama de financiación para los gobiernos locales en Colombia a través de los proyectos de inversión, que estén adscritos al banco de programas y proyectos en el ámbito local y/o nacional. De forma esquematizada recopiló información de las fuentes de financiación para las unidad operativa - presupuestaria en el que hay un objetivo establecidos, un sector, tiempo y recursos definidos. Con el Manual de Fuentes de Financiación para Proyectos de Inversión, el DNP pone a disposición de los gobiernos locales una fuente de consulta, como lo muestra la gráfica 1, que abarca los sectores de: industria y comercio, salud, comunicaciones, energía, vivienda, transporte, educación, justicia, medio ambiente, sector agropecuario, saneamiento básico, trabajo y seguridad sociales, vivienda, desarrollo comunitario, arte y cultura.

Gráfica 1. Impuestos municipales

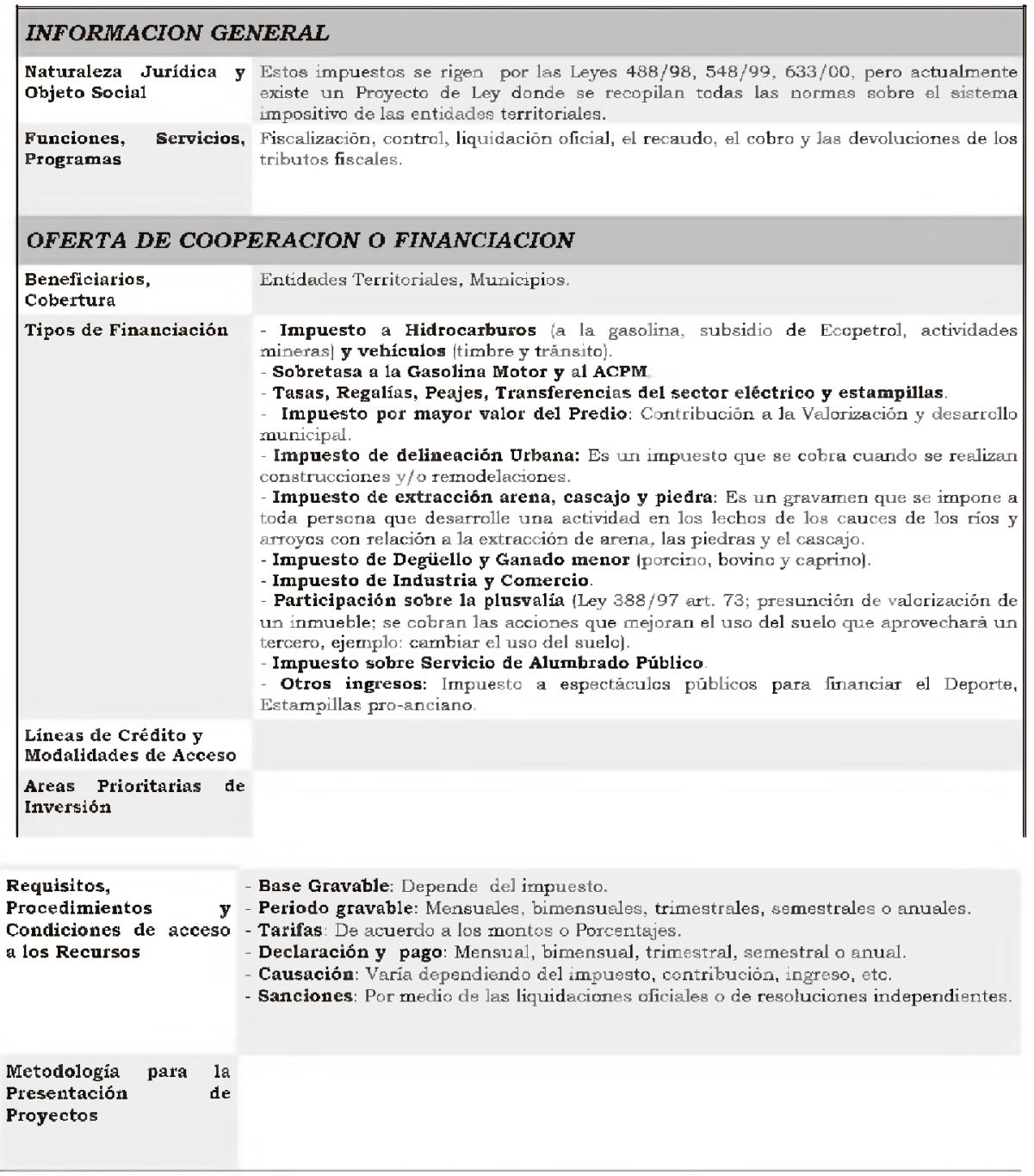

Tomado de: Departamento Nacional de Planeación (2003). Manual de Fuentes de Financiación para Proyectos de Inversión. P.79.

Por su parte, Juan Gonzalo Zapata, a través de Fedesarrollo, la Corporación Andina de Fomento (CAF) realiza un análisis de las finanzas de los gobiernos locales desde las ejecuciones presupuestales. Nótese en la gráfica 2 que el consolidado de la información de las finanzas locales está estructurado, en un mismo sentido, en relación con los ingresos, algunos de ellos son considerados mecanismos de financiación, y la ejecución presupuestal desglosada por rubros. Dicha gráfica presenta el consolidado de las ejecuciones presupuestales municipales, en un periodo de 2000 al 2008, y el autor concluye asertivamente: "el gran crecimiento de la actividad pública municipal. Tanto los ingresos como los gastos crecen a lo largo de los nueve años analizados y prácticamente se doblan a lo largo de la década. En general se ratifica el crecimiento de las principales fuentes de recursos de los municipios. Los ingresos corrientes pasan de $\$ 6.1$ billones a $\$ 11.7$ billones". (p.13) 
Gráfica 2. Consolidado Ejecuciones Presupuestales Municipales 2000 - 2009 (Miles de Millones \$ 2008)

\begin{tabular}{|c|c|c|c|c|c|c|c|c|c|}
\hline Municipics & 2000 & 2001 & 2002 & 2003 & 2004 & 2005 & 2006 & 2007 & 2008 \\
\hline INGRESOS TOTALES & 16,500 & 15,496 & 18,475 & 20,276 & 21,547 & 24,556 & 27,723 & 26,964 & 30,126 \\
\hline 1. NGRESOS CORRIENTES & 6,186 & 6,502 & 7109 & 8,395 & 9,443 & 10,442 & 11,834 & 11,389 & 11,673 \\
\hline 1.1 INGRESOS TRIBUTARIOS & 4,630 & 4,909 & 5,190 & 5,896 & 6,547 & 7,205 & 8,424 & 8,675 & 9,008 \\
\hline 1.1.1. PRED|AL & 1,599 & 1,648 & 1,756 & 1,925 & 2,152 & 2,347 & 2,507 & 2,475 & 2,533 \\
\hline 1.1.2. INDUSIRIA Y COMERCIO & 1,839 & 1,928 & 2,053 & 2,481 & 2,705 & 2,980 & 3,464 & 3,804 & 4,010 \\
\hline 1.1.3. SOBRETASA A LA GASOLINA & n.d & n.d & n.d & n.d & n.d & 1,177 & n.d & n.d & $1, \mathrm{C81}$ \\
\hline 1.1.4. OTROS & $\mathrm{n} . \mathrm{d}$ & m.d & n.d & 534 & 623 & 700 & n.d & n.d & 1,384 \\
\hline 1.2. INGRESOS NO TRIBUTARIOS & 940 & 978 & $\mathbf{1} 255$ & 1,722 & 2.188 & 2,488 & 2,607 & 1,915 & 1,771 \\
\hline 1.3. TRANSFERENCIAS & 616 & 615 & 663 & 777 & 708 & 748 & 804 & 800 & 895 \\
\hline GASTOS TOTALES & 18,433 & 16,532 & 19,325 & 20,687 & 20,862 & 24,108 & 28,033 & 30,208 & 28,327 \\
\hline 2. GASTOS CORRIENTES & 5,419 & 4,805 & 5,088 & 4.489 & 4,530 & 4.708 & 5.041 & 5.120 & 5,180 \\
\hline 2.1. FUNEIONAMIENTO & 4,685 & 4,137 & 4,294 & 4,107 & 4.020 & 4,237 & 4,521 & 4,679 & 4.542 \\
\hline 2.1.1. SERVICIOS PERSONALES & 2,128 & 2,078 & 1,735 & 2,040 & 1,985 & 2,119 & 2,158 & 2,189 & 2,177 \\
\hline $\begin{array}{l}\text { 2.1.2. GASTOS GENERALES } \\
\text { 2.1.3. TRANSFERENCIAS PAGADAS INOMINA }\end{array}$ & 976 & 794 & 810 & 789 & 770 & 773 & 803 & 930 & 732 \\
\hline 5) & 1,581 & 1,264 & 1,748 & 1,278 & 1,265 & 1,346 & 1,561 & 1,561 & 1.620 \\
\hline 2.2. NTERESES DEUDA PUB LICA & 693 & 579 & 794 & 300 & 510 & 470 & 499 & 428 & 638 \\
\hline 2.3. OTROS GASTOS CORRIENTES & 41 & 89 & & 82 & - & - & 21 & 12 & 12 \\
\hline 3. DEFICIT O AHORRO CORRIENTE \{1-2\} & 767 & 1,698 & 2,020 & 3,906 & 4,913 & 5,734 & 6,794 & 6,269 & 6.493 \\
\hline 4. INGRESOS DE CAPITAL & 10,314 & 8,993 & 11,366 & 11,881 & 12,103 & 14,115 & 15,889 & 15,575 & 18,452 \\
\hline 4.1. REGALIAS & 677 & 758 & 803 & 910 & 960 & 969 & 1,261 & 1,333 & 1,787 \\
\hline 4.2. TRANSFERENCIAS NALES [SGP, otrOS] & 6,807 & 5,982 & 7.774 & 9,788 & 10,354 & 11,063 & 11,444 & 11,981 & 13,320 \\
\hline 4.3. COFINANCIACION & 178 & 195 & 329 & 115 & 63 & 110 & 493 & 809 & 410 \\
\hline 4.4. OTROS & 2,652 & 2,057 & 2,460 & 1,067 & 727 & 1,972 & 2,691 & 1,453 & 2,935 \\
\hline 5.2. RESTO INVERSIONES & 6,867 & 7,945 & 8,991 & 10,199 & 11,496 & 12,746 & 14,769 & 15,033 & 16,619 \\
\hline
\end{tabular}

Tomado de: Zapata, p.15.

También, otra conclusión relevante fue: "el mejor resumen de la evolución del consolidado de las finanzas municipales se encuentra en el aumento de los recursos totales destinados a la inversión y a su vez la manera como esta financia. La mayoría de estos se destinan a inversión, pasan del $70 \%$ al $80 \%$, y esta, cada vez más se financia con recursos propios o de regalías" (p.14). De igual forma, Benavides y otros en el 2011 presentan un panorama general sobre las últimas dos décadas de financiación en infraestructura urbana en Colombia, que: "desde principios de los noventa los departamentos y municipios empezaron a recibir transferencias del gobierno central destinados en su mayoría a gastos en educación y salud. La descentralización administrativa quedó reglamentada en la Ley 60 de 1993" (p.1).
Asimismo, el sector de infraestructura es el de mayor inversión y demanda para los gobiernos locales (Benavides y otros, 2011). Estos autores plantean que las fuentes de obtención de recursos de los gobiernos locales van desde las "transferencias de orden nacional, que para el año 2009 alcanzaron los 10 billones de pesos. Como segunda fuente de recursos se tienen los ingresos tributarios hasta el año 2008, pues en el año 2009 fueron superados por los Recursos de capital" (p.10). La tabla 1 recopila las fuentes de financiación que establecieron los mismos autores para los gobiernos locales, y las ubica en la relación de gasto público y finanzas públicas.

Tabla1. Fuente de Financiación de los gobiernos locales: caso departamento de Antioquia

\begin{tabular}{|c|c|}
\hline FUENTE DE FINANCIACIÓN & CARACTERÍSTICAS \\
\hline Bancos municipales &  \\
\hline
\end{tabular}




\begin{tabular}{|c|c|}
\hline Bonos municipales & $\begin{array}{l}\text { "El mercado de bonos municipales es muy extenso y } \\
\text { profundo, y es la principal fuente de financiación de las } \\
\text { inversiones municipales en ese país. El apoyo federal a este } \\
\text { instrumento ha sido la exención tributaria y la contribución al } \\
\text { fondeo de fondos rotatorios públicos y bancos de bonos, que } \\
\text { hacen pooling de necesidades de los pequeños municipios" } \\
\text { (p.75) }\end{array}$ \\
\hline Fondos de desarrollo municipal & $\begin{array}{l}\text { "Desde el punto de vista de la gobernanza y los incentivos, } \\
\text { los fondos de desarrollo municipal pueden conv ertirse en un } \\
\text { monopolio institucional de diversas actividades relacionadas } \\
\text { con el financiamiento: preparación y evaluación de } \\
\text { proyectos, interventoría de construcción, financiación, } \\
\text { recolección de repagos de la deuda, etc. En un país con las } \\
\text { condiciones in stitucionales de Colombia, un fondo de este } \\
\text { tipo sería susceptible de captura política. Ésta podría darse a } \\
\text { pesar de seguir directrices de separación de actividades, } \\
\text { productos y gobierno corporativo." (p.76) }\end{array}$ \\
\hline $\begin{array}{l}\text { Pooling e intermediarios financieros } \\
\text { públicos para el gobierno local con reglas } \\
\text { de mercado. }\end{array}$ & $\begin{array}{l}\text { "Los diseños de los países emergentes, que se han } \\
\text { desarrollado en las últimas dos décadas, se orientan a usar } \\
\text { más los mercados de capitales domésticos e instrumentos } \\
\text { financieros como el pooling de grupos de mun icipios con el } \\
\text { fin de reducir costos de transacción a para acceder a los } \\
\text { mercados de crédito; una modalidad posible son los } \\
\text { intermediarios financieros públicos para el gobierno local con } \\
\text { reglas de mercado (Market-Based Local Government } \\
\text { Financial Intermediaries, MLGFls).(p.76) }\end{array}$ \\
\hline $\begin{array}{l}\text { Instrumentos de captura de valor del suelo. } \\
\text { En Colombia a través de la Ley } 388 \text { de } \\
1997 .\end{array}$ & $\begin{array}{l}\text { Para Fedesarrollo (2011: “ Schneider (2004) se concentra en } \\
\text { cuatro aspectos innovadores de la captura de valor: (i) } \\
\text { repartición de beneficios por d esarrollo conjunto urbano (por } \\
\text { desarrollo de nuevos negocios, o redesarrollo en zonas } \\
\text { deprimidas); (ii) financiación y desarrollo conjuntos de la } \\
\text { infraestructura entre sector público y operador; (iii) desarrollo } \\
\text { conjunto de tránsito arrendando espacios ale daños o } \\
\text { encontrando usos comerciales atractivos a lo largo de las } \\
\text { líneas, en las estaciones o en áreas adyacentes a las } \\
\text { mismas y (iv) desarrollo orientado al tránsito (generación de } \\
\text { nuevos flujos internos o en suburbios)." (p.83) }\end{array}$ \\
\hline
\end{tabular}

Fuente: elaboración propia con base en Benavides y otros (2011). Documento "Financiación de infraestructura y el desarrollo urbano.

Relación entre gestión pública y mecanismos de financiación estipulados normativamente para los gobiernos locales en el departamento de Antioquia

En Omar Guerrero (1990) la gestión pública tiene sus raíces en la década del $60 \mathrm{~s}$, cuya influencia es anglosajona, radica en la teorías de las organizaciones, que supere el pleonasmo entre manejo y accionar público, y de paso a la racionalización de egresos, incremento de ingresos y reducción del aparato estatal. A su vez, la new publicmanagement NGP nueva gestión pública-, para (Pollit y Bouckaert, 2000) citado por López (2003) es un "modelo convencional" que se reconoce básicamente como "una serie de cambios intencionales de las estructuras y procesos de organizaciones del sector público con el objetivo de que funcionen mejor -en algún sentido" (p.9). Al respecto señala Guerreo (1990):

\footnotetext{
Unos más, finalmente, se han encarrilado en el nuevo manejo público y han adoptado la voz inglesa management como estandarte representativo de un nuevo campo del conocimiento intermediario entre la administración pública y la administración de negocios privados: el "management público" ("managementpublic") (p.298)
}

La gestión pública incluye la orientación doctrinaria en la agenda de la reforma burocrática especialmente en Antioquia, por medio de la racionalización del presupuesto público, es decir, con qué recursos financieros se cuenta y cuáles son los frentes de inversión.

4 - En consonancia con la teoría de los costos de transacción de Ronald Coase. Ver Coase, R. (1937). “The Nature of the Firm”. Economical Vol. 4 , No. 16 (Nov.), pp. 386-405. Reimpreso en:, Olivier E. Williamson and Scott Masten, eds. The Economics of Transaction Cost. Elgar Critical Writings Reader. 1999,pp. 3-22. 
Esto implica que los mecanismos de financiación de los gobiernos locales en el departamento de Antioquia necesariamente responden al modelo de la gestión pública que concibe el Estado gubernamental desde como indica Osborne y Gaebler (1992) un: Gobierno catalizador, Gobierno competitivo, Gobierno inspirado por misiones, Gobierno orientado hacia los resultados, Gobierno orientado hacia los clientes, Gobierno empresarial, Gobierno descentralizado, Gobierno de la comunidad, Gobierno previsor y Gobierno orientado al mercado. (Santana y Negrón, 1996:1-5). Por su parte, la Organización para La Cooperación y el Desarrollo Económicos OCDE $(2008)^{5}$ desde finales de los años setenta, al impulsar la flexibilización de controles administrativos. Asimismo, rescata principios de economía, eficiencia y eficacia con énfasis en legitimidad, flexibilidad, asegurar desempeño, control, responsabilidad, fortalecer las funciones del gobierno, es decir, todo actuar orientado hacia resultados. En la gráfica 3 se muestra la estructura de la gestión pública en Colombia, donde la racionalización de las estructuras gubernamentales, revisión de procesos, toma de decisiones, direccionamiento de competencias y eficacia de los servicios, se traduce en gestión pública.

Gráfico 3. Elementos fundamentales de la Gestión Pública en Colombia

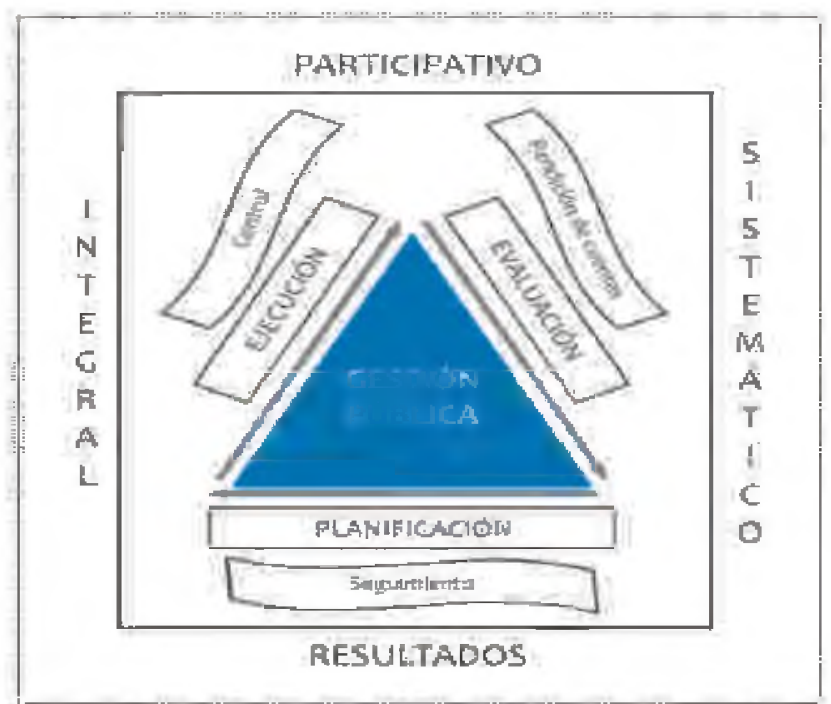

Fuente: Tomado del Departamento Nacional de Planeación y la Escuela Superior de Administración Pública. (2007). Gestión Pública Local. Página 11.
La gestión pública incorpora la figura políticoadministrativa de los municipios como gobierno locales, y no sólo un enfoque sistémico, un punto de vista meramente institucional u orgánico, radica en la organización del Estado para satisfacer las demandas sociales mediante, primero la disponibilidad de recursos financieros para la producción de bienes, servicios, disciplina y racionalización del uso de los recursos públicos. Es la capacidad de fortalecer la estructura administrativa-presupuestal al mismo tiempo que enfrenta incorpora el modelo gerencial basado en Reinventing Government (Rhodes, 1996).

Frente a los mecanismos de financiación la gestión pública plantea su orientación a resultados en concordancia a la capacidad de autogestión de los gobiernos locales para viabilizar los planes de desarrollo. Es decir, la gestión pública da un viraje filosófico -administrativo al quehacer administrativopresupuestal y técnico- procedimental, ya que no es el gobierno central quien gestiona los recursos para el desarrollo territorial, sino el propio gobierno local el encargado de hacerlo .Asimismo con resultados y métodos gerenciales privados (Rodríguez y Tapia, 2008), además implementar un modelo gerencial gubernamental, evaluación del desempeño, autonomía $\mathrm{y}$, ante todo, holgura fiscal.

En esa medida, como lo muestra la tabla 2, evidencia y consolida las fuentes o de financiación para los gobiernos locales, según a la Ley 152 de 1994, que posibilita la planificación y ejecución del plan de desarrollo local. Precisamente, estas fuentes son mecanismos de financiación en el marco de la gestión pública, porque delimitan administrativapresupuestariamente los deberes, tamaño y funciones de los gobiernos locales en el departamento de Antioquia, frente a la cuantificación y financiación de sus gastos e inversión social.

5 - "La OCDE constituye un foro único en su género, donde los gobiernos trabajan conjuntamente para afrontar los retos económicos, sociales y medioambientales que plantea la globalización. La OCDE está a la vanguardia de los esfuerzos emprendidos para ayudar a los gobiernos a entender y responder a los cambios y preocupaciones del mundo actual, como el gobierno corporativo, la economía de la información y los retos que genera el envejecimiento de la población. La Organización ofrece a los gobiernos un marco en el que pueden comparar sus experiencias políticas, buscar respuestas a problemas comunes, identificar buenas prácticas y trabajar en la coordinación de políticas nacionales e internacionales" OCDE Definición Marco de Inversión Extranjera Directa. Cuarta Edición (2008:2). 
Tabla 2. Fuentes - mecanismos de financiación de los gobiernos locales desde la norma

\begin{tabular}{|c|c|c|c|}
\hline \multirow[t]{2}{*}{ Tipo de ingreso } & \multirow[t]{2}{*}{ Características } & \multicolumn{2}{|c|}{ Gobiernos locales } \\
\hline & & Departamentos & Municipios \\
\hline Tributarios & $\begin{array}{l}\text { - Tienen carácter } \\
\text { obligatorio. } \\
\text { - Son generales, según } \\
\text { su base gravable. } \\
\text { - Son exigidos } \\
\text { coactivamente, si es del } \\
\text { caso. }\end{array}$ & $\begin{array}{l}\text { Registro y anotación } \\
\text { - Licores } \\
\text { - Cerveza } \\
\text { - Cigarrillos y tabaco } \\
\text { - Degüello de ganado } \\
\text { mayor } \\
\text { - Sobretasa consumo } \\
\text { gasolina motor } \\
\text { - Estampillas }\end{array}$ & $\begin{array}{l}\text { - Circulación y tránsito } \\
\text { - Predial unificado } \\
\text { - Telefonía } \\
\text { - Sobretasa ambiental } \\
\text { - Industria y comercio } \\
\text { - Avisos y tableros } \\
\text { - Publicidad exterior } \\
\text { visual } \\
\text { - Delineación y } \\
\text { urbanismo } \\
\text { - Espectáculos públicos } \\
\text { - Ocupación de vías } \\
\text { - Ventas por sistema de } \\
\text { clubes } \\
\text { - Rifas municipales } \\
\text { - Apuestas hípicas } \\
\text { - Degüello de ganado } \\
\text { menor } \\
\text { - Sobretasa bomberil }\end{array}$ \\
\hline No tributarios & $\begin{array}{l}\text { Se origina por la } \\
\text { explotación de de bienes } \\
\text { o servicios, prestación de } \\
\text { un servicio público, } \\
\text { transferencias y demás } \\
\text { recursos que no } \\
\text { correspondan a } \\
\text { impuestos. }\end{array}$ & $\begin{array}{l}\text { - Tasas o tarifas. } \\
\text { - Multas y sanciones } \\
\text { - Contribuciones }\end{array}$ & $\begin{array}{l}\text { - Tasas o ta rifas } \\
\text { - Multas y sanciones } \\
\text { - Contribuciones fiscales } \\
\text { - Participación en la } \\
\text { Plusvalía - captura del } \\
\text { valor de suelo de } \\
\text { conformidad con la Ley } \\
388 \text { de } 1997 \\
\text { - Peajes } \\
\text { - Otros ingresos no } \\
\text { tributarios }\end{array}$ \\
\hline Regalías & $\begin{array}{l}\text { Una contraprestación } \\
\text { económica por concepto } \\
\text { de explotación de } \\
\text { recursos naturales no } \\
\text { renovables. }\end{array}$ & \multicolumn{2}{|c|}{$\begin{array}{l}\text { Debe incorporarse al presupuesto territorial en un } \\
\text { mediano plazo, el cual debe ser priorizado para } \\
\text { financiar megaproyectos, por lo general } \\
\text { relacionados con infraestructura. De conformidad } \\
\text { con el Acto Legislativo del } 18 \text { de julio de } 2011 \text {; el } \\
\text { Decreto } 4923 \text { del } 26 \text { de diciembre de } 2011 ; \text { la } \\
\text { Resolución } 136 \text { de } 2012 \text {; la Ley } 1530 \text { del } 17 \text { de } \\
\text { mayo de } 2011 \text {; el Decreto } 4950 \text { del } 30 \text { de } \\
\text { diciembre de } 2011 \text {; el Decreto } 0051 \text { del } 13 \text { de } \\
\text { enero de } 2012 ; \text { el Decreto } 1074 \text { del } 22 \text { de Mayo } \\
\text { de } 2012 \text {. }\end{array}$} \\
\hline $\begin{array}{l}\text { Sistema General } \\
\text { de } \\
\text { Participaciones } \\
\text { SGP }\end{array}$ & \multicolumn{3}{|c|}{$\begin{array}{l}\text { Son recursos que la nación transfiere a los entes territoriales (municipios, } \\
\text { departamentos, di stritos y resguardos indígenas) para financiar las } \\
\text { competencia otorgadas en la Constitución. Son recursos estables y } \\
\text { permanentes. } \\
\text { A través del gobierno central los gobiernos locales tienen la facilidad de } \\
\text { financiamiento y/o cofinanciación de los proyecto s establecidos en los Planes } \\
\text { de Desarrollo Local. A través de la Ley } 715 \text { de } 2001 \text { que establece el Sistema } \\
\text { General de Participaciones SGP y competencias territoriales, reglamentadas } \\
\text { en la Ley } 1176 \text { de } 2007 \text { y } 60 \text { de } 1993 \text {, las cuales establecen los montos y } \\
\text { especificación de los gobiernos locales en los SGP. O a través del Fondo de } \\
\text { Ahorro Público y los Fondos de inversión que tiene el gobierno nacional. }\end{array}$} \\
\hline Cofinanciación & \multicolumn{3}{|c|}{$\begin{array}{l}\text { Están suscrito a principios de la planeación, según la Ley } 152 \text { de } 1994 \text { como: } \\
\text { Coordinación y Desarrollo armónico de las regiones. Dependen de la } \\
\text { capacidad de gestión y el impacto regional de la planificación local. La } \\
\text { cofinanciación se da en el ámbito departamental, nacional e internacional. }\end{array}$} \\
\hline $\begin{array}{l}\text { Recursos del } \\
\text { Crédito }\end{array}$ & \multicolumn{3}{|c|}{$\begin{array}{l}\text { Es la solicitud del crédito con entidades financieras locales, nacionales e } \\
\text { internacionales, de conformidad con la Ley. (ver tabla } 3 \text { ) }\end{array}$} \\
\hline
\end{tabular}

Fuente: elaboración propia con base en la Ley 152 de 1994. 
La siguiente gráfica recoge lo planteado en la tabla 2, en la medida que presenta el porcentaje de las fuentes o mecanismos de financiación de los gobiernos locales, en Antioquia, según Ley 152 de 1994, pero a escala nacional, en un periodo entre 1996 a 2009. De tal manera que la mayor inversión y mecanismos de financiación están en el Sistema General de Participaciones (color azul), que oscila en un promedio de $40 \%$ del total de los ingresos de los gobiernos locales; esto indica la fuerte dependencia de los gobiernos locales, especialmente los del departamento de Antioquia, a este recurso.

Gráfica 4. Porcentaje de inversión de los gobiernos locales por total de fuentes de financiación

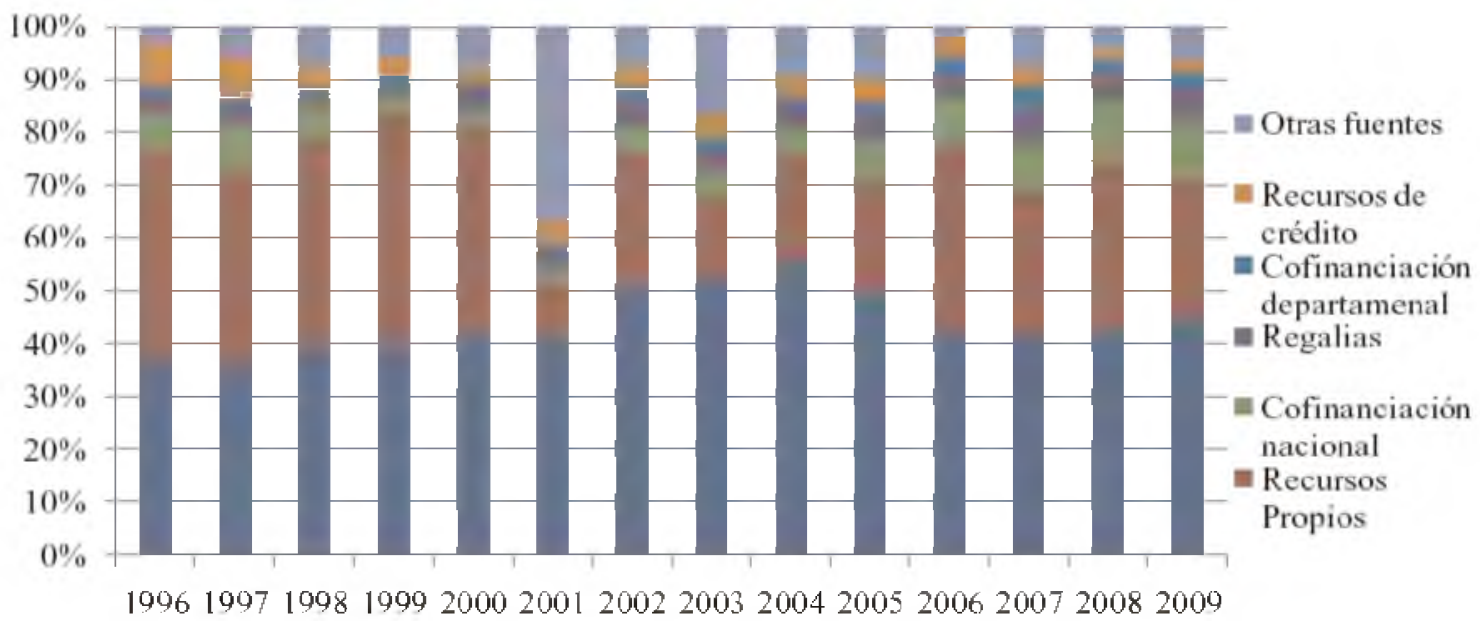

Tomado de Benavides y otros (2011).P. 21

De igual forma, el mecanismo de financiación que radica en los recursos propios como el tipo de ingresos tributarios y no tributarios es la segunda fuente de financiación de los gobiernos locales, representa un promedio del 30\%. Nótese los porcentajes de inversión, por Decreto 111 de 1996, deben relacionarse con los ingresos. Además nótese que el menor porcentaje de inversión es el recurso del crédito, con un promedio de 5\%, con excepción del año 1996 y 1997 que estuvo en un 8\%; esto se debe a la aplicabilidad de la Ley 617 en el año 2000.

Crédito bancario como mecanismo de financiación de mayor recurrencia para los gobiernos locales de Antioquia y su relación con la sostenibilidad de la deuda pública

Es importante resaltar que otro mecanismo de financiación con que cuenta los gobiernos locales del departamento de Antioquia, es el recurso del crédito. Sin embargo, este mecanismo cuenta con una regulación normativa por parte del gobierno central, a través de la Ley 358 de 1997, que garantice el control y la capacidad de pago de los gobiernos locales. Si bien, la tabla y gráfica anterior presentó los mecanismos de financiación, especialmente el crédito bancario para los gobiernos locales constituye una opción para la inversión local, según Lozano (1998): "las transferencias que reciben los municipios de la nación alivian su carga fiscal y, al igual que la deuda e constituyen en la principal fuente de expansión del gasto público" (p.1). A su vez el crédito público es considerado en los registros de la deuda pública, así lo señala Contraloría General de la Nación (2014):
Es preciso señalar que para efectos del registro de la deuda pública, en Colombia se han considerado las operaciones de crédito público definidas en el artículo 3 del Decreto 2681 de 1993 , el parágrafo $2^{\circ}$ del artículo 41 de la Ley 80 de 1993 y los artículos 10 y 13 de la Ley 533 de 1999 , así como los actos asimilados a operaciones de crédito de que trata el artículo $4^{\circ}$ del Decreto 2681 de 1993, que corresponde al alcance de la definición que se utilizará en este informe" (p.8).

Así que, el recurso del crédito público para Novoa (2006) como fuente de financiación se enfoca en la gerencia de proyectos de inversión, que compara objetivos y resultados esperados. La autora expone, especialmente a FONADE como aquella entidad donde las entidades estatales trasladan "la gestión técnica, administrativa, jurídica y financiera para el desarrollo de sus programas y proyectos, garantizando el buen término de los mismos". (p42.). Igualmente, el crédito público necesariamente se mide en la deuda pública, su aumento o disminución permite tener un panorama del manejo y disciplina presupuestaria que exige la gestión pública. Al respecto Asobancaria (2012) señala:

Gracias a la disciplina y el nuevo marco institucional, se recuperó el grado de inversión para la deuda pública en 2011, se espera que tenga lugar pronto una mejora de la calificación y el riesgo soberano se encuentra en mínimos históricos (p.12).

Por su parte, los gobiernos locales direccionan los recursos obtenidos a través del crédito bancario, como se ha dicho, a la inversión social, pero en materia administrativa - presupuestaria, de forma inmediata este crédito hace parte en la estructuración y definición de 
las cuentas locales, que la Ley 358 de 1997 estableció en relación con indicadores como: Interés Deuda ${ }^{6}$ /Ahorro Operacional ${ }^{7}$ y Saldo de la deuda ${ }^{8} /$ Ingresos $^{-}$ Corrientes $^{9}$, en el artículo $6^{\circ}$ :

Ninguna entidad territorial podrá, sin autorización del Ministerio de Hacienda y Crédito Público, contratar nuevas operaciones de crédito público cuando su relación intereses/ahorro operacional supere el $60 \%$ o su relación saldo de la deuda/ingresos corrientes superen el $80 \%$ Para estos efectos, las obligaciones contingentes provenientes de las operaciones de crédito público se computarán por un porcentaje de su valor, de conformidad con los procedimientos establecidos en las leyes y en los reglamentos vigentes.
De ahí que, como lo indica la tabla 3 , en materia de deuda pública se despliega todo un compendio de políticas presupuestarias (decreto 111 de 1996) para lograr su sostenibilidad, planes administrativospresupuestarios de desempeño y racionalización del gasto público, es decir, ingresos y egresos. Asimismo, la deuda pública se considera en relación a la Ley 617 de 2000 , ya que arroja la radiografía del estado presupuestario de los gobiernos locales, y que el sistema financiero considera al momento de otorgar un crédito público. Según la Presidencia de la República y otros (2009) la Ley presenta "una estructura financiera sana para el presupuesto en los municipios, permite incrementar los recursos propios y acceder a recursos adicionales que ayudan a financiar programas $y$ proyectos incluidos en el Plan de Desarrollo" (p.6).

Tabla 3. Normativa de endeudamiento para gobiernos locales

$\begin{array}{ll}\text { Constitución Política de Colombia } 1991 . & \\ \text { Art } 345 & \begin{array}{l}\text { Establece que no podrá haber ingreso ni gasto público que no se halle incluido en el } \\ \text { presupuesto. }\end{array}\end{array}$

LEY 51 DE 1990

Autoriza las operaciones para el saneamiento de obligaciones crediticias entre entidades públicas y el sistema financiero, a su vez, autoriza el endeudamiento interno ${ }^{a}$.

Reordena la deuda interna de la Nación y la búsqueda del Saneamiento de obligaciones crediticias del sector público.



Decreto 111 de 1997

Establece la estructuración y definición de la programación y ejecución del presupuesto público, tomado del Marco Fiscal del Mediano Plazo, el Plan de inversiones y el Plan Operativo Anual de Inversiones.



Fuente: Elaboración propia. 
Así, en materia de crédito bancario las entidades financieras deben considerar la evaluación de la capacidad de pago de los gobiernos locales del departamento de Antioquia, es decir, la aplicabilidad que tienen estos gobiernos del Decreto 696 de 1998, presentado en el informe de cierre fiscal de los gobiernos locales y establecer la tasa de interés en consideración del igual o menor porcentaje al ahorro operacional sobre el porcentaje del saldo de la deuda. Así superar lo que indica la Agencia Francesa para el Desarrollo y fundación ciudad humana (2014): "el mercado de la deuda del sector público local poco se ha desarrollado en la mayoría de los países de la región. Los bancos privados muestran poco interés por este tipo de deuda, lo que se traduce en tasas de interés que a menudo son elevadas $y$, sobre todo, ante la falta de inversionistas institucionales de largo plazo, en una fuerte aversión para proponer préstamos a largos plazos, lo que implica recurrir regularmente a operaciones de refinanciamiento" (p. 30).

De manera que los gobierno locales del departamento de Antioquia conforme a lo planteado en la tabla 3, tiene toda una fortaleza normativa para que el crédito público-deuda pública sea un mecanismos de financiación, y así, garantizar control y disminuir el riesgo de no pago que el sistema financiero considera inminente en Colombia (Agencia francesa para el Desarrollo y fundación ciudad humana, 2014). En esa medida, frente al objetivo del presente artículo, la identificación de los mecanismos de financiación para los gobiernos locales en el departamento de Antioquia, el crédito público parte de una fuerte capacidad financiera local para solventarlo. La tabla 4 evidencia el comportamiento de este mecanismo de financiación en siete gobiernos locales del departamento de Antioquia.

Tabla 4. Comportamiento de la deuda pública en municipios de Antioquia

\begin{tabular}{|c|c|c|c|c|c|}
\hline \multirow{2}{*}{$\begin{array}{r}\text { MUNICIPIOS - } \\
\text { GOBIERNOS } \\
\text { LOCALES }\end{array}$} & \multicolumn{5}{|c|}{ COMPORTAMIENTO DE LA DEUDA PÚBLICA ('Millones de pesos corrientes) } \\
\hline & Saldo 2009 & Saldo 2010 & Saldo 2011 & Saldo 2012 & Saldo 2013 \\
\hline MEDELLÍN & 209.658 & 208.146 & 200.545 & 511.419 & 843.499 \\
\hline BARBOSA & 1.936 & 1.474 & 934 & 9.614 & 7.828 \\
\hline BELLO & 49.712 & 56.184 & 51.057 & 62.312 & - \\
\hline CAÑASGORDAS & 166 & 419 & 876 & 685 & 756 \\
\hline CAUCASIA & 9.470 & 5.983 & 5.150 & 4.688 & 7.731 \\
\hline CALDAS & 717 & 9.018 & 8.819 & 10.591 & 12.118 \\
\hline APARTADÓ & 16.845 & 18. 186 & 20.433 & 25.073 & 22.186 \\
\hline
\end{tabular}

Fuente: elaboración propia con base en del Departamento Nacional de Planeación (2013). Informe saldo de Deuda de Departamentos y Municipios $2000-2013$.

6 - Son los pagados durante la vigencia + los causados que van a ser pagados en el resto de la vigencia + los de los créditos de corto plazo + los de sobregiros + los de mora + los del nuevo crédito que deban ser cancelados en la vigencia fiscal.

7 - Es el resultado de restar de los ingresos corrientes, los gastos de funcionamiento y las transferencias pagadas por las entidades territoriales. Articulo $2^{\circ}$ Ley 358 de 1997.

8 - De acuerdo al artículo $15^{\circ}$ de la Ley 358 de 1997 es la deuda de la vigencia anterior +desembolsos realizados a la fecha de cálculo amortizaciones realizadas a la fecha de cálculo.

9 - Según artículo $2^{\prime}$ Ley 358 de 1997 son: los tributarios, los no tributarios, las regalías, las compensaciones monetarias efectivamente recibidas, las transferencias nacionales, las participaciones en rentas de la nación, los rendimientos financieros, los recursos del balance.

10 - Como señala Miguel Gandour Pordominsky: "Antes de la constitución de 1991 el Gobierno tenía también bastantes prerrogativas con respecto al manejo del gasto: (i) el ministro de Hacienda era, en la práctica, mediante los Acuerdos de Obligaciones, quien autorizaba el presupuesto; (ii) el Gobierno tenía la potestad para decretar gasto cuando el Congreso no estaba sesionando; (iii) la metodología de cálculo de las transferencias a las entidades territoriales le daba al Gobierno un margen de discrecionalidad importante para determinar la asignación de gasto; (iv) el Ejecutivo podía reducir los salarios de los servidores públicos como medida de ajuste fiscal; y (v) los costos de terceros para hacer exigibles los compromisos legales y contractuales de la administración eran elevados. Esas capacidades se redujeron de forma drástica en el nuevo arreglo institucional. En materia monetaria (i) se prohibió el uso de la Cuenta Especial de Cambios; (ii) se expidió una reglamentación para la aprobación de créditos al Gobierno por parte del emisor que redujo su acceso a los mismos a una posibilidad teórica; (iii) se estableció que la compra de títulos de deuda pública sólo podía realizarse mediante operaciones de mercado abierto; y (iv) los recursos por señoreaje desaparecieron como fuente de financiamiento del Gobierno". (2008, p. 82 ) Tomado de la Revista Colombia Internacional 68, jul - dic. Pp. 68 - 97. Recuperado en file:///C:/Users/alexandra/Downloads/-data-Revista_No_68-06_Analisis.pdf.

11- Esta Decreto está en correlación con lo establecido por Ministerio de Hacienda y Crédito Público (1998) al señalar: En los dos primeros casos (Fndeudamiento autónomo e intermedio) existen dos procedimientos posibles a seguir- 1)Si con el nuevo crédito el incremento del saldo de la deuda de la vigencia anterior no supera la meta de inflación fijada por el Banco de la República para la vigencia actual, la entidad territorial podrá contratar el crédito autónomamente, es decir, no requerirá autorizaciones distintas a las dispuestas en las leyes vigentes. (Saldo deuda de la vigencia anterior + Nuevo crédito a contratar) - 1 × $100<$ D Meta de Inflación Saldo deuda de la vigencia anterior. 2) Si con el nuevo crédito el incremento del saldo de la deuda de la vigencia anterior supera la meta de inflación fijada por el Banco de la República para la vigencia actual, la entidad territorial no podrá celebrar la nueva operación de crédito público sino con autorización de endeudamiento, condicionada a la adopción de un Plan de Desempeño tendiente a restablecer la solidez económica y la capacidad de pago de la entidad. (Saldo deuda de la vigencia anterior + Nuevo crédito a contratar) - 1 × $100>$ D Meta de Inflación Saldo deuda de la vigencia anterior. Además de solicitar una autorización del Ministerio de Hacienda para contratar el crédito y establecer y cumplir un plan de desempeño. (p. 7) 
Nótese que los gobiernos locales año a año incrementan su deuda, sin embargo, el Municipio de Medellín es quien mayor presenta incremento en su saldo, entre el 2011 al 2012 de 310.874 (millones de pesos) y entre 2012 y 2013 de 332.080 (millones de pesos), solo con disminución de 1.512 y 7.601 (miles de pesos) entre los años 2009 y 2011 respectivamente. Los municipios de Cañasgordas y Caucasia entre el 2011 y el 2012 disminuyeron el saldo de la deuda en 191 y 462 (millones de pesos) respectivamente. Para el año 2012 y 2013 los municipios de Barbosa y Apartadó presentan una disminución del saldo de la deuda de 1.786 y 2.887 (miles de pesos) respectivamente, pero los demás municipios mantienen la constante de incremento. Asimismo, de la información contenida en la tabla 4 se concluye que, el crédito público es un mecanismo de financiación constante en estos gobiernos locales para alcanzar el desarrollo local. Para complementar y afianzar lo señalado en la tabla anterior, la tabla 5 presenta la relación entre la categorización de estos mismos gobiernos locales, según la Ley 617 de 2000.

Tabla 5. Relación Ley 617 de 2000 con la Ley 378 de 1997 y el Decreto 696 de 1998

\begin{tabular}{|c|c|c|c|c|c|}
\hline $\begin{array}{c}\text { MUNICIPIOS- } \\
\text { GOBIERNOS } \\
\text { LOCALES }\end{array}$ & $\begin{array}{c}\text { Categorización } \\
\text { Ley } 617 \text { de } \\
\text { 2000, vigencia } \\
2012 \text {. Fuente } \\
\text { Gobernación de } \\
\text { Antioquia (2012) } \\
\end{array}$ & $\begin{array}{c}\text { Ingresos } \\
\text { corrientes= } \\
\text { Ingresos } \\
\text { tributarios + } \\
\text { Ingresos no } \\
\text { tributarios + } \\
\text { Transferencias } \\
\text { corrientes } \\
\text { (millones de } \\
\text { pesos) }\end{array}$ & $\begin{array}{c}\% \text { de límite de } \\
\text { funcionamiento } \\
\text { en relación con } \\
\text { los Ingresos } \\
\text { Corrientes de } \\
\text { Libre } \\
\text { Destinación. } \\
\text { Fuente } \\
\text { Gobernación } \\
\text { de Antioquia } \\
\text { (2012) } \\
\end{array}$ & $\begin{array}{c}\text { Gasto de } \\
\text { funcionamiento } \\
\text { año } 2012 . \\
\text { Fuente } \\
\text { Gobernación } \\
\text { de Antioquia } \\
\text { (2012) } \\
\end{array}$ & $\begin{array}{c}\text { Aplicabilidad de la Ley } 358 \\
\text { de } 1997 \text { y Decreto } \\
\text { reglamentario } 696 \text { de } 1998\end{array}$ \\
\hline MEDELLÍN & Especial & 1.963 .404 & $50 \%$ & $38,7 \%$ & $\begin{array}{l}\text { A } 2012 \text { Endeudamiento } \\
\text { autónomo }\end{array}$ \\
\hline BARBOSA & tercera & 31.829 & $70 \%$ & $57,7 \%$ & $\begin{array}{l}\text { A } 2012 \text { Endeudamiento } \\
\text { autónomo }\end{array}$ \\
\hline BELLO & primera & 220.579 & $65 \%$ & $56,9 \%$ & $\begin{array}{l}\text { A } 2012 \text { Endeudamiento } \\
\text { autónomo, Sin embargo, el } \\
\text { Municipio cuenta con } \\
\text { capacidad de endeudamiento } \\
\text { pero no cuenta con } \\
\text { presupuesto para atender el } \\
\text { servicio de la deuda de } \\
\text { nuevos préstamos } \\
\end{array}$ \\
\hline CAÑASGORDAS & sexta & 14.010 & $80 \%$ & $69,8 \%$ & $\begin{array}{l}\text { A } 2012 \text { Endeu damiento } \\
\text { autónomo }\end{array}$ \\
\hline CAUCASIA & quinta & 52.054 & $80 \%$ & $63,2 \%$ & $\begin{array}{l}\text { A } 2012 \text { Endeudamiento } \\
\text { autónomo }\end{array}$ \\
\hline CALDAS & segunda & 29.965 & $70 \%$ & $46,1 \%$ & $\begin{array}{l}\text { A } 2012 \text { Endeudamiento } \\
\text { autónomo }\end{array}$ \\
\hline APARTADO & cuarta & 104.206 & $80 \%$ & $57.4 \%$ & $\begin{array}{l}\text { A } 2012 \text { Endeudamiento } \\
\text { autónomo. }\end{array}$ \\
\hline
\end{tabular}

Fuente: elaboración propia con base en Gobernación de Antioquia (2012). Informe de viabilidad fiscal municipios de Antioquia - vigencia 2012 Para la información de Medellín, Secretaria de Hacienda del Municipio de Medellín (2012) Informe de análisis de la deuda pública del Municipio de Medellín. Para Bello, Secretaria de Hacienda del Municipio de Bello (2012) Informe indicadores de solvencia y sostenibilidad. Demás municipios Contraloría General de Antioquia (2012) Informe fiscal y financiero.

De la tabla anterior se concluye que los sietes gobierno locales del departamento de Antioquia, cada uno en categoría distinta, cumplen los requerimientos de Ley 617 de 2000 en materia de saneamiento fiscal y, ante todo, el cumplimiento de uno de los principios de la gestión pública, la eficacia administrativa -presupuestaria en la racionalización de los recursos propios, esto es, los Ingresos Corriente de Libre Destinación ICLD. Sin embargo, nótese que el Municipio con el menor porcentaje de ICLD destinados para el funcionamiento es Medellín, categoría especial, y el Municipio con mayor porcentaje en gastos de funcionamiento es Cañas gordas, categoría sexta, lo que evidencia una disparidad político-administrativa y presupuestaria en materia de holgura fiscal que garantice mayor inversión social, fin último de los mecanismos de financiación aquí señalados.

Es decir, la Ley 617 de 2000 evidencia una desigualdad fiscal en los sietes gobiernos locales del departamento de Antioquia, en la medida que la viabilidad y realidad de los mecanismos de financiación para estos gobiernos varían según sus capacidades financieras en la gestión del recurso público. Además, tanto la Ley 152 de 1994, Ley 617 de 2000 como el Decreto 111 de 1996 establecen mecanismos de financiación para estos gobiernos, al tiempo que exigen disciplina fiscal para su administración. Como indican Quintero y Álvarez (2005):

12 - Según informe ejecutivo de la Contraloría Municipal de Bello: "Informe fiscal y financiero municipio de Bello". Consultado en el link: file://C:/Users/Usuario/Downloads/04-INFORME-FISCAL-Y-FRO.pdf 
Los resultados acerca del impacto de la Ley 617 de 2000 sobre los Gf (gastos de funcionamiento) como porcentaje de los Icld (ingresos corrientes de libre destinación) son consistentes para los diferentes niveles territoriales (municipal y departamental), y por lo tanto conducen a una conclusión global: la ley tuvo un significativo impacto sobre aquellos GCT (gobiernos centrales territoriales) considerados como tratados al inicio del análisis empírico, que se manifiesta en una mayor solvencia fiscal para financiar sus Gf. En otras palabras, los resultados sugieren que la norma fue efectiva y consecuente con sus objetivos, aunque su incidencia no pueda generalizarse para la totalidad de municipios y departamentos del país. El análisis empírico indica, además, que el comportamiento de los GCT no tratados en relación con el porcentaje explicado, responde en el período probablemente a las condiciones iniciales, al verse una proporción de Gf en promedio menor que la de los GCT tratados. (p.36).

En materia de aplicabilidad de la Ley 358 de 1997 y el Decreto reglamentario 696 de 1998 (normativización del mecanismo de financiación del recurso del crédito), estos siete municipios a 2012 presentan un indicador de "Endeudamiento autónomo", lo que indica financieramente, se tiene solvencia y sostenibilidad para el pago de la deuda, excepto el municipio de Bello que no cuenta con presupuesto para atender el servicio de la deuda de nuevos préstamos.. Es de aclarar que el nivel de endeudamiento de estos sietes gobiernos locales de Antioquia está mediado por indicadores de solvencia (Interés /ahorro operacional) y sostenibilidad (Saldo de la Deuda / Ingresos corrientes) que determinan, por un lado, la cobertura del servicio de la deuda durante la vigencia fiscal, y por otro lado, se tiene o no capacidad de inversión.

Sin embargo, nótese de la tabla 4 y 5 que la capacidad de endeudamiento está circunscrita a los ingresos corrientes, es decir, el gobierno local con mayores ingresos corrientes tendrá mayor capacidad de endeudamiento y por ende de pago, pero el gobierno local con menores ingresos corrientes tendrá que ser más rigurosos al momento de adquirir un crédito público, por una parte, debe cumplir la Ley 617 de 2000 en el porcentaje de gastos de funcionamiento $y$, por otra parte, garantizar sostenibilidad de la deuda.

Alianzas público-privadas mecanismo de financiación alterno para los gobiernos locales de Antioquia, en el marco de la gestión pública.

Es loable para los gobiernos locales del departamento de Antioquia garantizar otro mecanismo de financia- ción, no solo limitado a los ingresos corriente, sistema general de participaciones, regalías, recursos del crédito, sino que permita mayor despliegue políticoadministrativo para cumplir el fin constitucional (artículo 2 y 311 C.N de 1991). Precisamente, una mecanismo de financiación alternativo son las Alianzas Público-Privadas APP, a través de la presentación de proyectos de desarrollo local-regional, como señala Ribera (2000) Citado por Sáenz (2012) bajo "una secuencia única de actividades complejas e interconectadas que tienen un objetivo o propósito que debe ser alcanzado en un plazo establecido, dentro de un presupuesto y de acuerdo con unas especificaciones" (p. 11). Además dentro del marco de la planeación local y el gobierno proactivo que promulga la gestión pública.

Las Alianzas Público- Privadas APP se enfocan a la inversión social y al fortalecimiento institucional de los gobierno. Las AAP para América Latina y en especial para Colombia surgen como un instrumento para suplir el déficit, por un parte en infraestructura, y por otra parte, el financiero para atender las demandas sociales. Estas Alianzas están inmersas en los principios de la gestión pública: eficiencia, eficacia y administrar orientado a resultados. Expandir los vínculos y las relaciones de los estados a escala de integración mayor que permanentemente busque el desarrollo técnico, financiero, gerencial y considera otros actores claves, como agentes privados para el desarrollo social y económico.

Por otra parte, las AAP están bajo la concreción de consensos y estrategias que movilicen y contribuyan a cada sector: público, privado y la misma sociedad civil organizada (ver gráfica 5), es decir, voluntades políticas y económicas. Además, las APP como mecanismos de financiación para los gobiernos locales del departamento de Antioquia, en el marco de la gestión pública, están basadas en los principios de: racionalización económica, efectividad, capacidad para el análisis estratégico, horizontalidad y potenciación de las capacidades organizacionales, así? como la concreción de redes interinstitucionales. Por otra parte, son una unidad operativa de actividades interrelacionadas y encaminadas a un fin, buscan mayor eficacia y eficiencia en la prestación de los servicios públicos, además de garantizar la sostenibilidad de los recursos para la financiación del desarrollo local. 
Gráfica 5. Contribución a cada sector con las alianzas público-privadas.

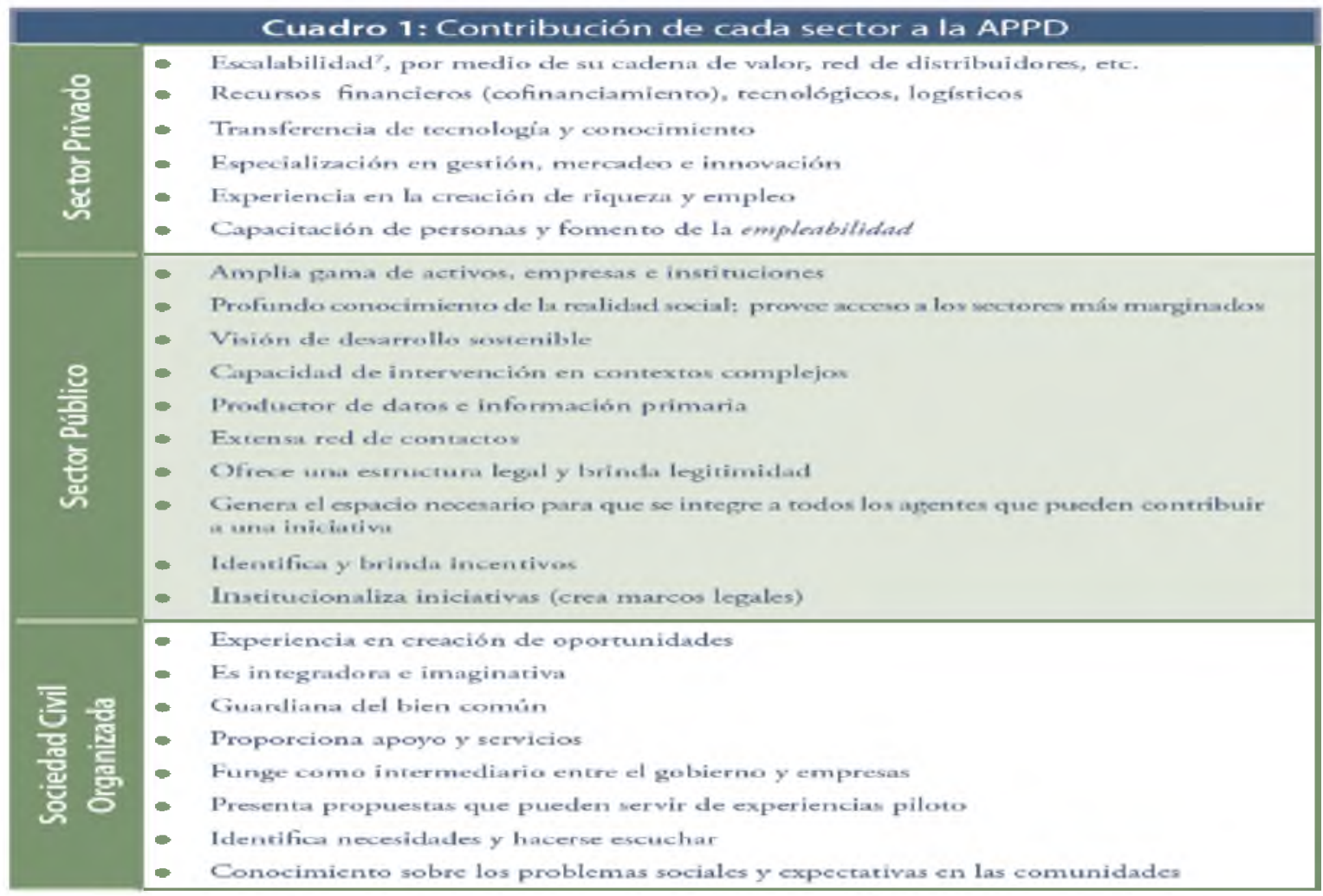

Fuente: Cardona y Sariego (2010, p.7)

Las APP como mecanismos de financiación para los gobiernos locales del departamento de Antioquia, a través de proyectos locales-regionales de inversión pública, están contemplados en el marco normativo de la Ley 152 de 1994 en principios consagrados como son: subsidiaridad, complementariedad y concurrencia. Por ende, toda APP se considera cooperación, como clave para el logro de resultados, como lo señala la Agencia Noruega de Cooperación para el Desarrollo NORAD (2012): "subraya los lazos lógicos entre los insumos previstos, las actividades planeadas y los resultados esperados" (p.17). A través de las APP, los gobiernos locales del departamento de Antioquia pueden realizar un mapeo de sus recursos disponibles y cuáles son los riesgos y las responsabilidades de las partes. La gráfica 6 manifiesta la importancia de que las APP sean medibles y verificables financieramente.

Gráfica 6. Siete posibles recursos que puede brindar cada socio a la alianza.

\begin{tabular}{|l|l|}
\hline \multicolumn{1}{|c|}{ Tipo de Recurso } & \multicolumn{1}{c|}{ Ejemplo } \\
\hline Financieros & $\begin{array}{l}\text { Dinero en efectivo, fideicomisos, crédito a incerés preferencial, } \\
\text { incentivos de precios en el marco de cadenas de suplidores }\end{array}$ \\
\hline Materiales & $\begin{array}{l}\text { Productos, maquinaria, transporte, espacio para el desarrollo de } \\
\text { acrividades }\end{array}$ \\
\hline Recurso Humanó & $\begin{array}{l}\text { Voluntariado, experiencia en administración, gerencia, mercadeo, } \\
\text { apoyo técnico }\end{array}$ \\
\hline Contactos organizacionales & $\begin{array}{l}\text { Socios de negocios, organizaciones internacionales, sindicatos y otras } \\
\text { asociaciones laborales, asociaciones de desarrollo comunal, grupos } \\
\text { religiosos, medios de comunicación }\end{array}$ \\
\hline Recolección de información & $\begin{array}{l}\text { Daros estadísticos, información de mercado, conocimiento local y } \\
\text { sectorial }\end{array}$ \\
\hline Difusión de información & $\begin{array}{l}\text { Comunicación electrónica, comunicación de boca en boca, redes } \\
\text { sociales, publicaciones }\end{array}$ \\
\hline Capacidad degeneraciónderecursos & $\begin{array}{l}\text { Personal con experiencia en desarrollo de proyectos, campańas y } \\
\text { eventos, contactos con donantes internacionales y locales }\end{array}$ \\
\hline
\end{tabular}

Fuente: Cardona y Sariego (2010, p.33) 
Por tanto, las Alianzas Público -Privadas APP como mecanismo de financiación alternativo para los gobiernos locales de Antioquia se reglamentan en la Ley 1508 de 2012, su artículo $\mathrm{N}^{\circ} 1$ las define como un "instrumento de vinculación de capital privado, que se materializan en un contrato entre una entidad estatal y una persona natural o jurídica de derecho privado". Además está esta Ley incentiva una nueva generación de concesiones, los proyectos de dividen en etapas para detallar su financiación por parte de los gobiernos locales e inversionistas privados. Las APP es instrumento político - presupuestario manifiesto en: contratos de obras o servicios públicos, concesiones y contratos de participación pública- privada, bajo reglamentaciones proteccionistas, que garantizan los servicios públicos para lo público y contratos de largo plazo, en que la parte privada, en especial los organismos internacionales y privados locales, prometen proporcionar un servicio global, sostenibilidad y mantenimiento de infraestructura pública por el tiempo establecido en el contrato.

Al respecto señala la Agencia francesa para el Desarrollo y fundación ciudad humana (2014):

Gráfica 7. Pasos para las alianzas público -privadas APP
El potencial de las asociaciones público-privadas en el financiamiento del desarrollo urbano ha sido muy poco explotado, sobre todo debido a una madurez todavía insuficiente de los mecanismos de asociación. Por esta relativa falta de experiencia, en ocasiones ha generado decisiones en el modo de gestión que no dan seguridad al socio privado, procedimientos poco propicios para licitaciones dinámicas, o una elaboración de contratos que garantizan el control y la preservación del interés del socio público. Las experiencias de las entidades territoriales francesas y europeas, que disponen de una mayor perspectiva sobre el ciclo de vida de las asociaciones público-privadas, podrían resultar de gran interés para las entidades territoriales latinoamericanas. (P. 42)

Así que, para establecer las APP como iniciativa de los gobiernos locales de Antioquia es necesario apalancar esfuerzos y maximizar impactos positivos como: mejoramiento la gobernanza local en el logro de los objetivos del desarrollo, distribuye y promueve la incorporación de tecnologías y procesos administrativos a la gestión pública local, por último, contribuye a la sostenibilidad de la ejecución del plan de desarrollo. Como muestra la gráfica 7 , es necesario preguntarse por el método para establecer una APP, que parte, como indican Devlin y Moguillansky (2009), de un proceso político-administrativo transparente, optimización de recursos público, mejor garantías, servicios y beneficiarios.

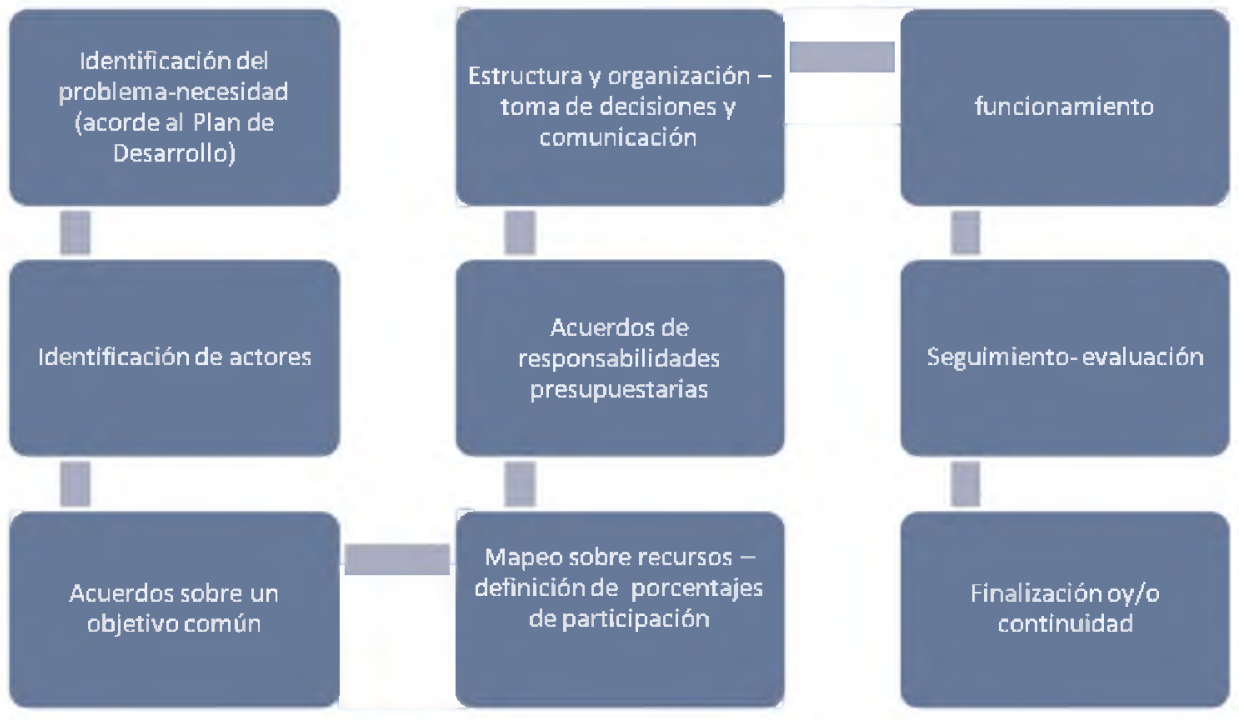

Fuente: elaboración propia.

Sin embargo, es de considerar que el sector en el que mayormente se presentan las APP es el de infraestructura (Benavides y otros, 2011). Precisamente, como indica el Banco Interamericano de Desarrollo BID (2012) no debe tomarse a la ligera, ni considerarlas como la panacea, por tanto, se debe estudiar las fortalezas, debilidades, oportunidades y amenazas, que van desde la voluntad política, la capacidad administrativa -presupuestaria de las partes y trasparencia, que en los gobiernos locales se traduce en procesos de contratación en consideración de la Ley 80 de 1993, la Ley 1150 de 2007 y su Decreto Reglamentario 2474 de 2008. Además, definir tiempo, recursos, pólizas de cumplimiento y los gobiernos locales no pierda de vista el interés público, sin ser absorbido por el interés particular. 
Por otra parte, las AAP son armonizadas fiscal y económicamente a través de mecanismo de financiación estipulado en la Ley 152 de 1994, la cofinanciación, y esto representan en la inversión de los gobiernos locales en el departamento de Antioquia un promedio de $7 \%$. Igualmente, las APP se presenta a escala local, nacional y mundial, en cuatro estrategias políticas, administrativas y presupuestarias: I) estructuras financieras y condiciones locales, como el análisis de las condiciones locales, capacidad institucional y técnica. II) conciliación de intereses, en el que se procure el interés general. III) estudio de las necesidades del gasto público de forma sectorizada y en el marco del plan de desarrollo IV) estudios de riesgos y pre-factibilidad de los proyectos desde establecer un mapa de riesgos (medición -mitigación). Al respecto señala la Devlin y Moguillansky (2009).

Ante todo, las alianzas público-privadas solo representarán una herramienta eficaz para la estrategia de desarrollo si el Estado colabora estrechamente con el sector privado pero retiene su autonomía en lo que concierne a salvaguardar el bienestar público o lo que Evans (1995) -un pionero de la política industrial moderna- denomina "autonomía enraizada". Solo así el Estado podrá mostrarse como un socio activo del sector privado y evitar, al mismo tiempo, quedar "cautivo" de intereses particulares (p.68)

Una posible Alianza Pública- Privada APP en el departamento de Antioquia es el circuito de los embalses presentado por la Gobernación de Antioquia en el en conjunto con los Concejos de los Municipios de: El Peñol, Guatapé, San Rafael, Alejandría, Concepción y San Vicente, en una "Sesión Simultánea" con Concejales, Alcaldes, representantes del Gobierno Departamental y Nacional, líderes políticos y representantes de algunas organizaciones, presentado en febrero de 2015. Es una actual propuesta de infraestructura vial, que comprende 172 kilómetros, de la siguiente manera: i) $106 \mathrm{Km}$ de Aplicación de nuevas tecnologías para el mejoramiento de las Superficies de Rodadura. (Tramos: Barbosa Concepción - Alejandría - Caza Diana; y Concepción San Vicente - La Y - El Peñol). ii) $39 \mathrm{Km}$ de Mejoramiento y Rectificación de Vías Pavimentadas. (Tramos: El Crucero - San Vicente; y Marinilla - El Peñol -Guatapé) y iii) $27 \mathrm{Km}$ de Rehabilitación de Vías Pavimentadas. (Tramos: Guatapé - Caza Diana - San Rafael). El proyecto tiene un costo de $\$ 500.000$ millones de pesos, que tendrá como fuentes de financiación: gobierno nacional 51\%, aportes regionales 15\%, Peajes $18 \%$, valorización sector eléctrico $16 \%$.

\section{Conclusiones}

Aproximarse a la identificación de los mecanismos de financiación para los gobiernos locales del departamento de Antioquia, en el marco de la gestión pública, es reconocerlos desde la ley. Estos mecanismos en principio son: ingresos propios (tributario y no tributarios) regalías, sistema general de participaciones, cofinanciación y recursos del crédito. Estos mecanismos normativamente deben abarcar acciones de gestión pública como: orientación a resultado y planeación estratégica a través de proyectos de desarrollo. Esto logra optimizar los recursos públicos, la innovación política, administrativa y presupuestaria, desde de tres elementos: I) competencias y capacidades. II) establecer parámetros y definir recursos en diferentes sectores contemplados desde el pan de desarrollo. III) toma de decisiones a partir de conocer cuáles son los mecanismos de financiación a los cuales tiene acceso los gobiernos locales desde la misma normativa y, sobre estos, procurar el desarrollo las Alianzas Público- Privadas.

En esa medida, la gestión pública en la cual se inscriben los mecanismos de financiación no solo para los gobiernos locales de Antioquia, sino de Colombia, son producidos por una lógica de globalización gerencial de lo público-gubernamental. Es claro que los principios que anuncia y establece la gestión pública, y que en anteriores párrafos fueron señalados, como la eficiencia, eficacia y la administración orientada a resultados, son considerados como la ruta de la modernización burocrática del Estado. Sin embargo, es de confrontar que justamente los mecanismos de financiación para los gobiernos locales responden a como lo indica Guerrero (2003, p 19) a "la cooperación y la coordinación intergubernamental. De aquí surge la noción del multigobierno junto con la ancestral idea de unigobierno, pues en la medida en que la globalización constituye un emblema del siglo XXI, los estados nacionales ejercitan su soberanía al mismo tiempo que incrementan sus relaciones con otros estados y con los organismos multinacionales".

Precisamente lo anterior permite establecer que los mecanismos de financiación para los gobiernos locales de Antioquia se fundamentan en lógicas de globalización política. Esto es, gobiernos locales fuertes que identifiquen y desarrollen capacidades y procesos de autonomía, holgura fiscal e integración económica, en igualdad de condiciones con otros gobiernos a escala local, regional y supraestatal. Gobiernos locales con capacidad financiera, económica, política y administrativa para gerenciar sus propios asuntos y superar por su propias capacidades las crisis fiscales que implica cumplir con calidad y oportunidad los servicios públicos que debe garantizar el Estado. As su vez, los objetivos que logren gobiernos deben ser motivados por técnicas gerenciales como: el gobierno local es un medio para alcanzar medios sociales; prioridad de la inversión social; el ciudadano es el eje de toda intervención política; y todas las acciones gubernamentales debe ser legitimadas por los ciudadanos.

Por otra parte, los recursos del crédito como mecanismo de financiación y que tiene mayor cuidado para su acceso, los gobiernos locales de Antioquia debe continuar con la disciplina y racionalización presupuestaria en el manejo de la deuda. Además de considerar lo dispuesto en el Decreto 696 de 1998 , reglamentario de la citada Ley 358, en el cual se estipula la prioridad en el sostenimiento de la deuda, 
dentro de un período establecido y suscrito entre el gobierno local y la entidad financiera-crediticia, que contenga: I) diagnóstico financiero e institucional. II) plan de acciones, medidas y metas. III) cronograma de ejecución; costos del plan de desempeño y fuente de financiación. IV) Proyecciones de los escenarios de evolución de las finanzas públicas.

Si bien el presente artículo presentó un consolidado de los mecanismos de financiación para los gobiernos locales del departamento de Antioquia, y que están definidos por Ley, aún falta que, al momento de tener un panorama político-presupuestario sobre la financiación pública para estos gobiernos, no se encasille la inversión pública en los mismos mecanismos de financiación, sino superar los limitantes políticos-administrativos y de gestión (modelos de gerencia, eficacia y eficiencia) que impregna la planificación del desarrollo local. Esto es, los gobiernos locales del departamento de Antioquia deben profundizar en mecanismos de financiación alternativos, no solo en las Alianzas Público-Privadas, sino, la financiación se inicie en la gestión y planificación del territorio local. Las APP para los gobiernos locales del departamento de Antioquia deben considerar desde dos principios: primero, tener gobernanza, como la capacidad de cohesión institucional entre la planificación y la programación presupuestal, que evite renegociaciones de las APP a través de la modalidad de contratos. Segundo: fortalecer la institucionalidad pública local a través de establecer los riesgos, responsables y costos/beneficios de estas Alianzas.

Por último, las APP deben articular, por una parte, participación en plusvalías como la captura del valor del suelo por alguna intervención urbana del gobierno local, a través de la implementación de los planes de ordenamiento territorial, y por otra parte, en el Pooling e intermediarios financieros públicos entre gobiernos locales, con reglas de mercado que como señaló Benavides y otros (2011) se logre por medio de la consolidación de redes de cooperación entre municipios que tienen mayor capacidad administrativa, financiera y técnica, fortalecer escenarios político-presupuestarios a escala urbano-regional, que facilite el acceso de los pequeños gobiernos locales a créditos e inversiones privadas.

\section{Referencias bibliográficas}

Agencia Noruega para la cooperación del Desarrollo NORAD (2012). El enfoque del Marco Lógico. Manual para la planificación de proyectos orientada mediante objetivos. Tercera edición. Madrid.

Asonbancaria (2012). Informe de semana económica del 10 de

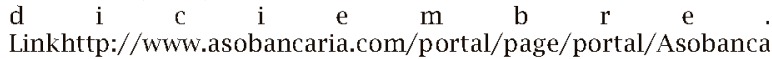
ria/publicaciones/economica_financiera/semana_economica/20 12 .

Agencia francesa para el Desarrollo y fundación ciudad humana. (2014). El financiamiento de las ciudades latinoamericanas. Herramientas para el desarrollo urbano sostenible. Pp 1-109.

Banco Interamericano de Desarrollo BID (2012). Alianzas públicoprivadas para mejorar la capacidad MSF: ¿Qué enseñanzas pueden extraerse de este enfoque cooperativo? http://www.oie.int/doc/ged/D13293.PDF

Benavides, J., Olivera, M., Arboleda, O y Quintero. P (2011).
Financiación de infraestructura y el desarrollo urbano.

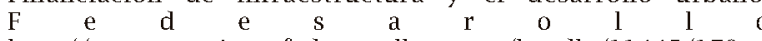
http://www.repository.fedesarrollo.org.co/handle/11445/179

Brugue, Q. y Subirats, J.(1996). Lecturas de Gestión Pública, MAP, Madrid.

Cardona, R., Sariego, L. (2010) Guía metodológica para la formulación y gestión de alianzas público-privadas para el desarrollo. Aliarse

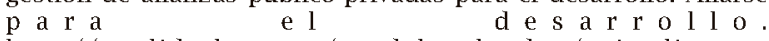
http://es.slideshare.net/guadalupelondon/guia-alianzaspublico-privadas-para-el-desarrollo

Contraloría General de la Nación. (2014). Situación de la Deuda Pública $\begin{array}{lllll}\text { C o l o m b i a n a } & 0 & 1 & 3\end{array}$ http://www.contraloriagen.gov.co/documents/10136/18696249 5/Informe+de+la+Situacl\%C3\%B3n+de+la+Deuda+P\%C3\%BAblica +Colombiana+2013.pdf/34533c19-bc8f-46d1-b18adalf66b7790a

Contraloría General de Antioquia (2012) Informe fiscal y financiero del Municipio de Apartado

Contraloría General de Antioquia (2012) Informe fiscal y financiero del Municipio de Barbosa.

Contraloría General de Antioquia (2012) Informe fiscal y financiero del Municipio de Cañasgordas

Contraloría General de Antioquia (2012) Informe fiscal y financiero del Municipio de Caucasia

Contraloría General de Antioquia (2012) Informe fiscal y financiero del Municipio de Caldas

Constitución Política de Colombia de 1991. Temis. 2011.

Congreso de la República de Colombia. Ley 819 de 2003. Diario Oficial No 45243

Congreso de la República. Ley 617 de 2000. Diario Oficial 44.188.

Congreso de la República. Ley 51 de 1998. Diario Oficial AÑO CXXVII. N. 39615

Congreso de la República. Ley 358 de 1997. Diario Oficial 42.2973

Congreso de la República. Decreto 111 de 1996. Diario Oficial 42.692

Congreso de la República. Ley 152 de 1994. Diario Oficial 41.450

Congreso de la República de Colombia, Ley 51 de 1990. Diario Oficial No. 39615 .

Departamento Nacional de Planeación (2013). Informe saldo de Deuda de Departamentos y Municipios 2000 - 2013. https://www.dnp.gov.co/programas/desarrolloterritorial/Paginas/saldo-de-deuda-de-departamentos-ymunicipios.aspx

Departamento Nacional de Planeación y la Escuela Superior de Administración Pública. (2007). Gestión Pública Local. Bogotá D.C.

Departamento Nacional de Planeación (2003). MANUAL FUENTES DE FINANCIACION PARA PROYECTOS DE INVERSION. http://www.unalmed.edu.co/tmp/proyectosmga/documento\%2 Denviados\%20proyectos/Manual\%20de\%20Fuentes\%20de\%20Fina nciacion.pdf

Devlin, R., y Moguillansky, G. (2009). Alianzas Público -Privadas para una nueva visión estratégica del desarrollo. CEPAL, Comisión Económica para América Latina y el Caribe. https://www.oas.org/es/sap/docs/dgpe/Alianzas_pub_privadas -s.pdf

Gobernación de Antioquia (2015). Presentación del megaproyecto "circuito de los embalses". Sesión Simultánea. Concejos de los Municipios de: El Peñol, Guatapé, San Rafael, Alejandría, Concepción y San Vicente.

Gobernación de Antioquia (2012). Informe de viabilidad fiscal municipios de Antioquia - vigencia 2012 . http://www.antioquia.gov.co/PDF2/informe_viabilidad.pdf

Gonzalo, J. (s.f). Las finanzas territoriales en Colombia. Fedesarrollo, la Corporación Andina de Fomento (CAF). h t t p:// w w w. f edesarrollo.org.co/w p content/uploads/2011/08/Las-finanzas-territoriales-enColombia-J-G-Zapata-Mayo-2010.pdf

Guerrero, M. (2008). La nueva Gestión pública. Un modelo privatizador del proceder del Estado. Alcances y consecuencias. Instituto de Administración pública del Estado de México. México. D.F.

Guerrero, O. (2003). Gerencia pública en la Globalización. Universidad Nacional Autónoma de México. México. D.F.

Guerrero, O. (1990). Teoría administrativa del Estado. Universidad Nacional Autónoma de México. México.D

Gunn, L. (1996). Perspectivas en gestión pública. En: Lecciones de Gestión Pública, MAP, Madrid. pp. 41-45

Hugues, O. (1996). La Nueva Gestión Pública", En: Lecturas de Gestión Pública, MAP,

Madrid. pp. 103-132.

López, A. (2003). La Nueva Gestión Pública: Algunas Precisiones para su abordaje conceptual. Serie I: Desarrollo Institucional y Reforma 
del Estado. Documento Nro. 68. Instituto nacional de la administración pública. Dirección de Estudios e Información.

Lozano, I. (1998). Las transferencias intergubernamentales y el gasto $\mathrm{p}$ ú b l i c o $\quad$ e n c o l o m b i a. http://www.banrep.gov.co/docum/ftp/borra099.pdf

Ministerio de Hacienda y Crédito Público. Decreto reglamentario 696 de 1998 .

Novoa, A. (2006). Fuentes de financiación y líneas de crédito en Colombia en la banca de segundo piso. Universidad nacional, Facultad de Ciencias Administrativa y económicas. Especialización en ingeniería financiera. http://www.bdigital.unal.edu.co/1099/

Osborne, D. \& Gaebler, T. (1992). Reinventing Government. How the Entrepreneurial Spirit is Transforming the Public Sector.Addison Wesley Publ.

Portinario, P. (2003). Estado. Léxico de Política. Ediciones nueva visón. Buenos Aires.

Presidencia de La República, Ministerio del Interior y de Justicia Escuela Superior de Administración Pública- ESAP y la Federación Nacional de Concejos - Fenacon (2009). Revista de trimestral del Gobierno Nacional y la Federación Nacional de Concejos para los concejos municipales y las entidades territoriales "Fuentes de financiación municipales" Bogotá D.C. marzo. Pp. 1-32.

Quintero, G. y Álvarez, D. (2005). Ley 617 de 2000 y su impacto fiscal territorial. Centro Regional de Estudios Económico CREE Medellín. Banco de la República. PP. 1- 56

Rhodes, R. (1996). The New Governance: Governing without Government. Political Studies, (44), 652-667.

Rodríguez, J. y Tapia, E. (2008). Pensamiento administrativo y organizaciones públicas II. Módulo del programa de administración pública territorial. Escuela Superior de Administración Pública ESAP. Bogotá D.C. pp. 8 -68.Saenz, A. (2012). Tesis El Éxito de la Gestión de Proyectos. Un nuevo enfoque entre lo tradicional y lo dinámico. $\mathrm{R}$ e c u p e r a d o d e http://www.tdx.cat/bitstream/handle/10803/117483/Arturo_Saenz $\%$ 20Tesis_2012_Rev_1.pdf?sequence $=1$

Secretaria de Hacienda del Municipio de Medellín (2012). Informe de análisis de la deuda pública del Municipio de Medellín. https://www.medellin.gov.co/irj/portal/ciudadanos?NavigationTarg et=navurl://caf5ec8b258193efa09eae0909c6fee3

Secretaria de Hacienda del Municipio de Bello (2012) Informe indicadores de solvencia y sostenibilidad. http://www.bello.gov.co/index.php/contabilidad-y-presupuesto 